\title{
DUCTILITY AND FLEXURAL BEHAVIOR OF ONE WAY CONCRETE SLABS REINFORCED WITH LOCAL GFRP REBARS: AN EXPERIMENTAL AND ANALYTICAL STUDY
}

\author{
Sherif H. Al-Tersawy ${ }^{\mathrm{a}}$, M.A.Ghanem ${ }^{\mathrm{b}}$ \\ ${ }^{a}$ Lecturer, Civil Eng. Dept., Higher Technological Institute, $10^{\text {Th }}$ - of Ramadan City, Egypt. \\ Mobile: 0201225626715 EMAIL: al_tersawy@ @otmail.com \\ ${ }^{b}$ Lecturer, Mech. Dept., Faculty of Industrial Education, Suez canal University, Egypt.
}

\begin{abstract}
The need for an alternative to steel reinforcement (RFT) in areas of severe environmental conditions and areas sensitive to magnetic fields has emerged the use of Fiber Reinforced Polymers (FRP). Experimental and analytical studies of FRP reinforcement are still less than that of steel RFT. In this study, seven slabs reinforced with local Glass Fiber Reinforced Polymers (GFRP) were tested under four points bending configuration. Load-deflection behavior, as well as strains in slabs, was recorded in order to investigate slab's ductility and flexural behaviors. The main parameters of the experimental work included RFT ratio, and shear span to effective depth ratios $\left(\mathrm{L}_{\mathrm{sh}} / \mathrm{d}_{\text {eff. }}\right)$ Analytical models used to predict these behaviors were implemented in order to compare the results with experimental work. The results of this research work indicated that crack behavior and load deflection curves can be simulated using analytical models and can be reasonably used for the prediction of the behavior of the tested slabs.
\end{abstract}

\section{Keywords:}

GFRP; local rebars; slabs; ductility; flexure.

\section{1- Introduction}

Despite the fact, that corrosion is accelerated in cold countries due to low temperature and the use of salts in the deicing process [1-3], the corrosion problem is initiated also in hot countries such as in the Middle East and Arabian Gulf as a result of hot weather and high level of humidity [4]. In both cases, FRP reinforcement emerged as a practical solution, not only because of its noncorrosive properties, but also due to its high strength to weight ratio, as well as its good fatigue resistance [5]. Among FRP types; such as Aramid (AFRP) and Carbon (CFRP); GFRP has the advantage of its low cost. However, the linear stress-strain relation and low modulus of elasticity of its material is a major concern for designers.

The elastic behaviors of FRP rebars, as well as the bond characteristics of FRP, affect strongly the ductility of members subjected to flexure such as beams and slabs [6]. This serviceability issue becomes the governing aspect in design rather than moment capacity of section [7]. As a result of this brittle nature of FRP, it was recommended to direct the flexural members to fail in compression rather failing in tension [7, 8]. In such a brittle characteristic, this type of failure is less catastrophic and is more progressive. In order to determine deflection of FRP reinforced beams, most codes guidelines adopted a simple elastic method;

Branson's equation [9]; and an effective moment of inertia equation to describe the reduced stiffness of cracked sections. The effective moment of inertia modified originally by ACI 316 [9] was adopted by ACI 440.1R-06 [7]. The design manual by ISIS Canada [8] proposed a more reliable code, implemented from Model code 90 [10], and was derived using tension stiffening effect. In Euro code 2 [11], the same tension stiffening model of Model code 90 was the basis for this guideline. The main concept of these guidelines is the estimation of deflection using integration of the beam's curvature along the flexural member. The Euro code method showed acceptable results for the prediction of FRP reinforced beams deflection [12]. Most experimental results in the available literature [13-16] showed higher ultimate moment capacities than those predicted by most codes guidelines.

In this research work, an experimental program was carried out in order to manufacture GFRP locally in the laboratories of the higher technological institute; $10^{\text {th }}$ of Ramadan city; Egypt (HTI) and the characteristics of rebars were measured to get its tensile strength and its modulus of elasticity, as well as its ultimate strains; a detailed study on the statistical properties of these local rebars will be presented in a future work by the same authors. The locally manufactured rebars were used for making seven concrete slabs, one of them is a control slab 
with conventional steel reinforcement and the other six slabs were divided into two series at which each series is of different shear span to effective depth ratio. In each series, three different GFRP reinforcement ratios were used including under, balanced, and over reinforcement ratios. All slabs were tested under four points bending configuration, and load-RFT strains, as well as, load-deflection relations were recorded during tests. Slabs were tested under the monotonically increased static-short term loads. Code guidelines, ACI440.1R-06, and Euro code 2 were applied on the tested beams. Theoretical load-deflection curves, as well as moment capacity, were evaluated. Finally, the modified ductility methods were used to evaluate the amount of reduction in ductility of GFRP reinforced slabs.

\section{Experimental work}

The aim of the experimental work is to test seven reinforced concrete slabs in flexure in order to record load-deflection curves and load-strain relations. Among the seven slabs specimens, six slabs were reinforced with a local GFRP rebars while the seventh one was reinforced with steel RFT. The GFRP reinforced slabs were divided into two groups at which the first group had $\mathrm{L}_{\mathrm{sh}} / \mathrm{d}_{\mathrm{eff}}$ in the range (5.45.6) while the second group had the ratio in the range of (7.5-7.8). Each group consisted of three different RFT ratios, under, balanced, and over reinforced ratios respectively.

\subsection{Materials}

The used GFRP had a surface treatment of sand coating and were tested in order to obtain its tensile strength and young's modulus, Table (1). The tension specimens were fixed to the grips of a universal machine (500 kN schumatzu universal machine) using a resin and sand filled steel tubes, and the strains were recorded using strain gauges. In order to study the variability of GFRP rebars, 10 specimens were tested, and the failure occurred in the rebar away from the steel tubes. The steel rebars were high grade steel with a mean proof stress of $40 \mathrm{MPa}$ and a mean ultimate stress of $60 \mathrm{MPa}$. The concrete mix was designed in order to produce a concrete with normal strength. Cement content was $350 \mathrm{~kg} / \mathrm{m}^{3}$, and the water cement ratio was 0.55 . The type of coarse aggregate was crushed dolomite with a maximum nominal size of $20 \mathrm{~mm}$. The average 28-days cylinder strength was $21 \mathrm{MPa}$.

Table (1) Mechanical properties of GFRP rebar

\begin{tabular}{|l|c|}
\hline $\begin{array}{l}\text { Guaranteed Rupture tensile strength, } \\
f_{f u}\left(\mathrm{~N} / \mathrm{mm}^{2}\right)\end{array}$ & $470^{*}$ \\
\hline Modulus of elasticity, $E_{f}(\mathrm{Gpa})$ & 26 \\
\hline Guaranteed Rupture strain, $\varepsilon_{f u}$ & $2.3 \%{ }^{*}$ \\
\hline
\end{tabular}

* average of 10 specimens and calculated according to ACI 440-1R-06.

\subsection{Slabs details}

The first group of GFRP reinforced slabs is consisted of three slabs with length of $1.5 \mathrm{~m}$ while the second group is consisted of three slabs with length of $2.0 \mathrm{~m}$. the steel reinforced slab has a length of $2.0 \mathrm{~m}$. All slabs cross section dimensions were designated as S\#-XY, where $\mathrm{S}$ stand for slab, \# identify its number, $\mathrm{X}$ identify its length $(1.5 \mathrm{~m}$ or $2.0 \mathrm{~m}$ ), and $\mathrm{Y}$ identify its reinforcement ratio (Uunder reinforced, B-balanced, and O-over reinforced). The steel reinforced slab was given code S7-2 Steel. The distance between supports and end of slabs is $100 \mathrm{~mm}$ at both ends. The aim of the experimental program was to keep the ratio between shear span to the total effective depth to be $1 / 3$ for all tested slabs. This resulted in keeping the length of the maximum bending moment zone to be $1 / 3$ of the total effective span for all tested slabs. In all slabs, clear concrete cover is kept $25 \mathrm{~mm}$. The geometric details of slabs and its reinforcement details are given in Table (2) and Fig.(1).

The slabs were cast in two stages, in each stage, 3 standard cubes, 3 standard cylinders, and 3 standard beams were cast in order to determine the 28 days concrete strength, young's modulus, and modulus of rupture. All specimens were cured under similar conditions and tested on the same day. The tests were made according to ASTM C469-96 [17] and ASTM C469-94 [18] respectively. The slabs elements were covered with wet Hessian for one week then kept under standard conditions. All slabs and concrete samples were tested within 4-5 weeks after concrete placing time. The values of compressive strength, young's modulus, and modulus of rupture for concrete are shown in Table (3). 
Table (2) Geometric details and RFT for slabs

\begin{tabular}{|c|c|c|c|c|c|c|c|c|c|}
\hline \multirow{2}{*}{ Slab Code } & \multicolumn{3}{|c|}{ Dimensions (mm) } & \multirow{2}{*}{$\begin{array}{l}\text { RFT } \\
\text { Type }\end{array}$} & \multirow{2}{*}{$\begin{array}{l}\text { Main } \\
\text { RFT }\end{array}$} & \multirow{2}{*}{$\begin{array}{c}\text { RFT ratio } \\
\rho\end{array}$} & \multirow{2}{*}{$\begin{array}{c}\text { Secondary } \\
\text { RFT }\end{array}$} & \multirow{2}{*}{$\begin{array}{c}\text { Effective } \\
\text { Depth } \\
(\mathrm{mm})\end{array}$} & \multirow{2}{*}{$\begin{array}{c}\text { shear } \\
\text { span/effective } \\
\text { depth ratio }\end{array}$} \\
\hline & Length & Width & Height & & & & & & \\
\hline $\mathrm{S} 1-1.5 \mathrm{U}$ & 1500 & 500 & 120 & GFRP & $4 \phi 10$ & 0.008 & $5 \phi 10 / \mathrm{m}$ & 80 & 5.4 \\
\hline S2-1.5B & 1500 & 500 & 120 & GFRP & $6 \phi 12$ & 0.017 & $5 \phi 12 / \mathrm{m}$ & 79 & 5.5 \\
\hline $\mathrm{S} 3-1.5 \mathrm{O}$ & 1500 & 500 & 120 & GFRP & $6 \phi 16$ & 0.031 & $6 \phi 12 / \mathrm{m}$ & 77 & 5.6 \\
\hline S4-2U & 2000 & 500 & 120 & GFRP & $4 \phi 10$ & 0.008 & $5 \phi 10 / \mathrm{m}$ & 80 & 7.5 \\
\hline S5-2B & 2000 & 500 & 120 & GFRP & $6 \phi 12$ & 0.017 & $5 \phi 12 / \mathrm{m}$ & 79 & 7.6 \\
\hline S6-2O & 2000 & 500 & 120 & GFRP & $6 \phi 16$ & 0.031 & $6 \phi 12 / \mathrm{m}$ & 77 & 7.8 \\
\hline S7-2Steel & 2000 & 500 & 120 & Steel & 4T10 & 0.008 & $5 \mathrm{~T} 10 / \mathrm{m}$ & 80 & 7.5 \\
\hline
\end{tabular}

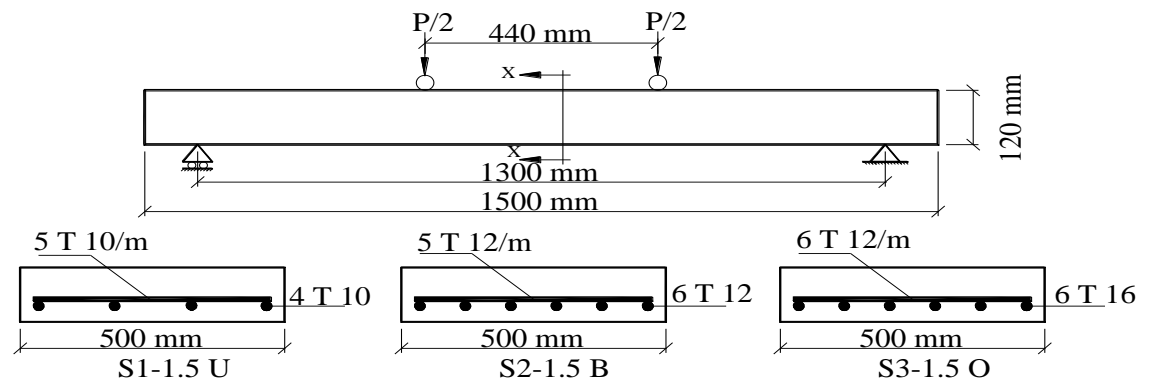

Dimentions and test set-up for Slabs (S1-S3)

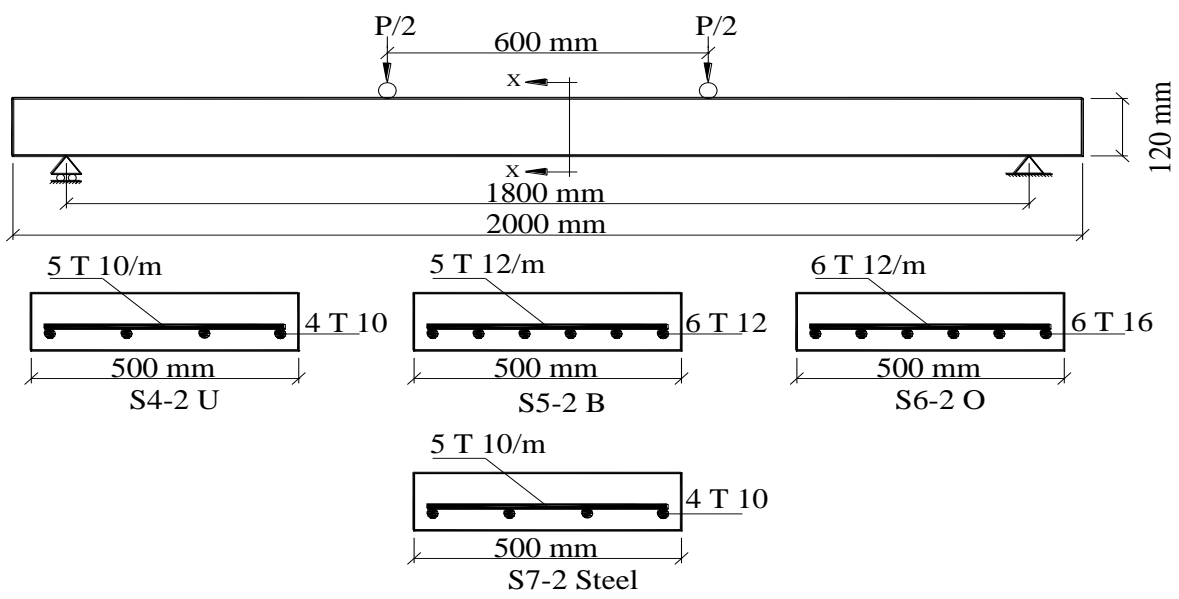

Dimentions and test set-up for Slabs (S4-S7)

Fig. (1) Slabs RFT and Loading setup

Table (3) Mechanical properties of Concrete

\begin{tabular}{|l|c|}
\hline Concrete 28 days strength, $f_{c}^{\prime}(\mathrm{MPa})$ & 21 \\
\hline Modulus of elasticity, $E_{c}(\mathrm{Gpa})$ & 21 \\
\hline Rupture stress, $f_{r}(\mathrm{MPa})$ & 2.9 \\
\hline
\end{tabular}




\subsection{Experimental setup and instrumentation}

As illustrated in Fig. (2), loads on slabs are applied using a hydraulic jack through a spreader steel beam. All data were collected using data acquisition system. The deflection of slabs was measured using 2 linear variable differential transducers (LVDTs), they were located under slab at the positions of the two concentrated loads. The third LVDT was located horizontally at the bottom of the slab to measure displacement in concrete. Horizontal bottom strains in GFRP rebars were measured using four strain gauges at different locations on the same rebar. The strain gauges were used to measure strains in a main RFT rebar (considering $1.5 \mathrm{~m}$ long slabs: two strain gauges were located $200 \mathrm{~mm}$ from slab center to the left and to the right, and two strain gauges were located $600 \mathrm{~mm}$ from slab centre to the left and to the right- for the $2.0 \mathrm{~m}$ long slabs: two strain gauges were located $150 \mathrm{~mm}$ from slab center to the left and to the right, and two strain gauges were located $450 \mathrm{~mm}$ from slab center to the left and to the right).

\section{Experimental results and discussions}

In the following section, a detailed description of the experimental results are presented then compared to the predictions obtained from theoretical approaches and codes guidelines. An analysis of the slabs behavior is presented. The analysis included crack behavior, crack width, load-deflection curves, strain profile along GFRP rebars, and ultimate load and deformability. Both serviceability and ultimate limit states are presented. It was recommended in literatures $[16,19]$, to evaluate serviceability at loads up to $35 \%$ of the ultimate load, and the same percentage is adopted in the current research work.

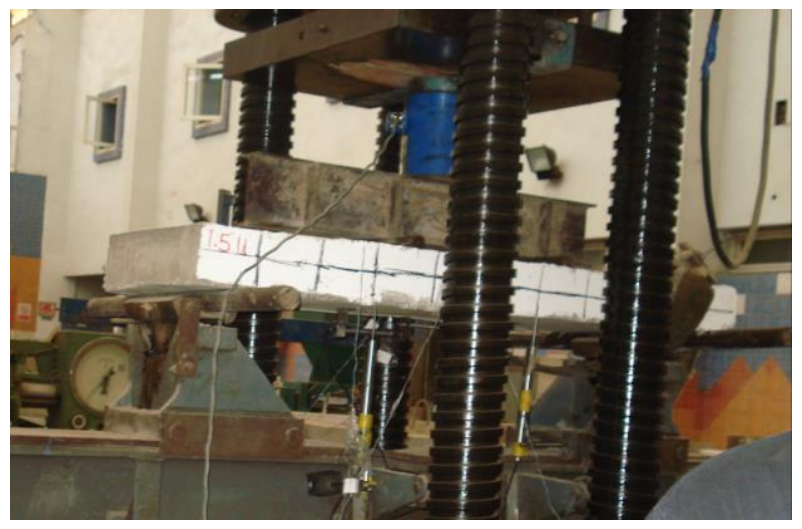

Fig. (2) Experimental setup

\subsection{Tension test results of GFRP}

Ten specimens were tested in tension in order to evaluate both ultimate tensile stresses as well as ultimate tensile strains for GFRP rebars. With the aid of the Faculty of Industrial Education University Labs located in Suez University, tests were performed using universal machine and strain gauges measured the strains in the rebars in the middle of the rebars; Fig. (3). The rupture occurred away from the circular metallic fixations used to fix the specimens to the grips of the universal machines. As expected, the behavior of all specimens was linear up to failure, Fig. (4) and Table (1) show tension test results.

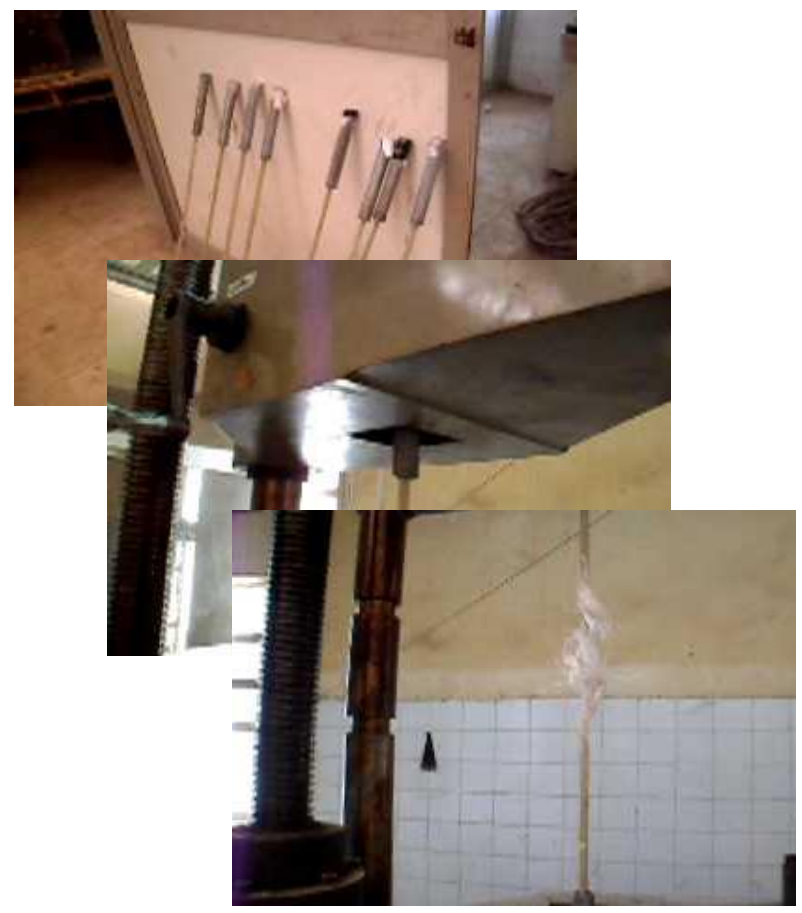

Fig. (3) Experimental setup for GFRP specimens

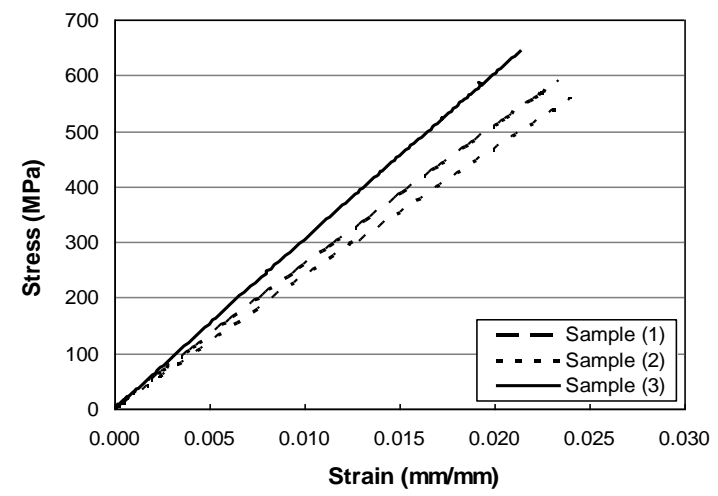

Fig. (4) A typical Stress-Strain curve for three GFRP specimens tested in tension 


\subsection{Crack behavior}

Fig. (5-a) and Fig. (5-b) show the crack loads and patterns for the tested slabs. Most of the cracks occurred at the location of the GFRP transverse rebars. Although GFRP rebars were coated with sand, the bond between it and concrete is still low and hence, the transverse GFRP rebars provided mechanical anchorage for the longitudinal reinforcement and controlled to some extent the spacing between cracks. In the slab reinforced with steel, where the bond between steel and concrete is relatively high, and the shear stress is transferred in a continuous manner, the cracks spacing is dependent on the bond quality and cracks initiates at areas where shear stress that is transferred from longitudinal steel bars to concrete exceeded the bond strength of steel. In FRP reinforced slabs, the mode of failure depends on both reinforcement ratio and $\mathrm{L}_{\mathrm{sh}} / \mathrm{d}_{\mathrm{eff}}$ ratio. Since the $\mathrm{L}_{\mathrm{sh}} / \mathrm{d}_{\mathrm{eff}}$ for slabs S1-1.5U, S2-1.5B, and S3-1.5O were very near to the shear limit ratio of slabs which is 5 , the mode of failure for the three slabs was shear, see Fig. (6) For slab S1 after the test as an example of shear failure. Slab S6-2O, where $\mathrm{L}_{\mathrm{sh}} / \mathrm{d}_{\text {eff }}$ equal 7.8 , failed in flexural shear as a result of failure of the concrete by a combination of diagonal shear and crushing, Fig. (7). It is noticed from the figure that the diagonal shear crack propagated between the interface of GFRP mesh and concrete toward the end of the slab.

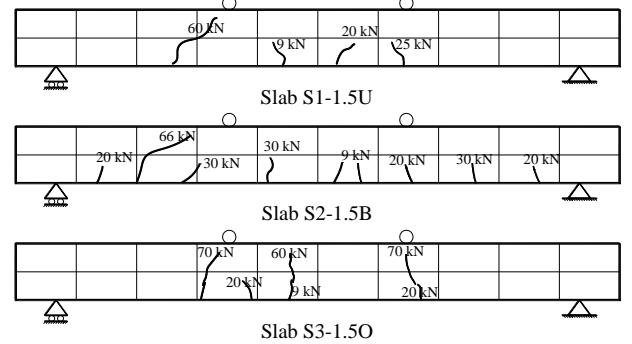

Fig. (5-a) Crack patterns for slabs (S1-S3)

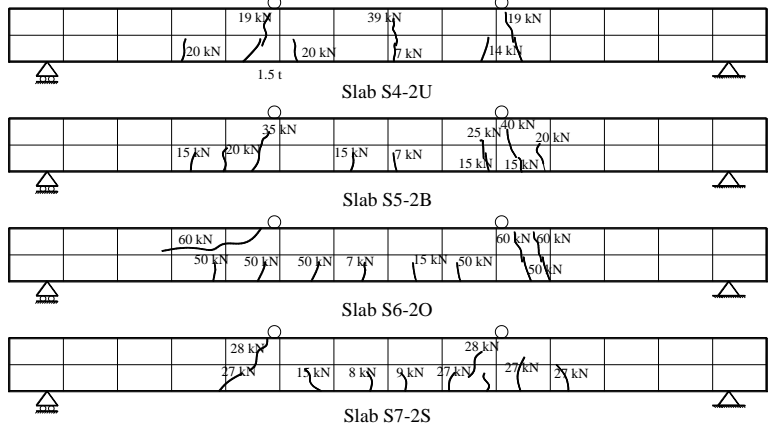

Fig. (5-b) Crack patterns for slabs (S4-S7)

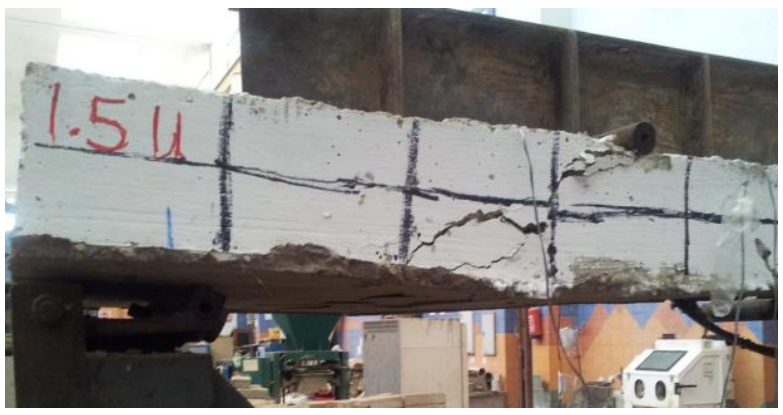

Fig. (6) Failure mode of slab S1-1.5U

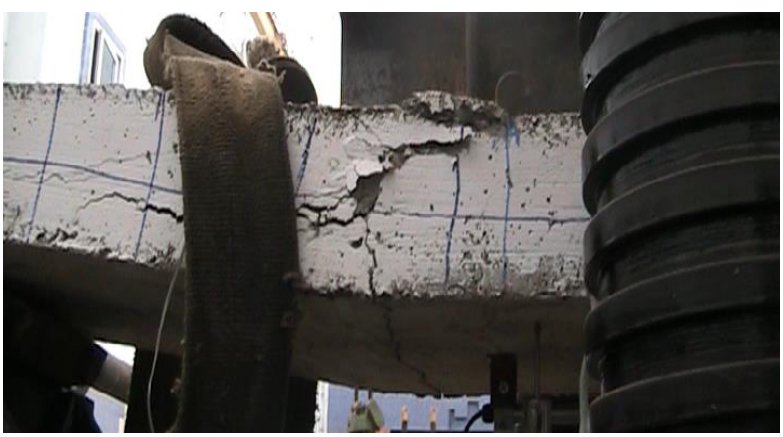

Fig. (7) Failure mode of slab S6-2O

The classical equation, Eq. (1), for the calculation of moment capacity at first crack, is used to calculate the theoretical first flexural crack moment.

$$
M_{c r}=\frac{f_{r}}{y_{t}} \times I_{g}
$$

Where: $M_{c r}$ is the cracking moment, $f_{r}$ the modulus for concrete and is calculated using Eq. (2), $I_{g}$ the gross moment of inertia for the slab section calculated at the centroid of the section, and $y_{t}$ is the arm between tension side of slab and centroid of section. The contribution of GFRP in the calculation of the moment of inertia of slabs is neglected.

$f_{r}=0.623 \lambda \sqrt{f_{c}^{\prime}}$

Where: $\lambda$ is the modification factor for concrete density and is taken 1 for normal concrete [20].

Fig. (8) Show a comparison between theoretical and experimental values of first crack moment while Table (4) show the theoretical first crack moment and crack width for GFRP reinforced slabs. It is obvious from the figure that the theoretical cracking 
moment is close to the experimental value especially considering slabs with $\mathrm{L}_{\mathrm{sh}} / \mathrm{d}_{\mathrm{eff}}$ in the range of (5.4-5.6) and can be used for estimating a close and realistic first crack moment values.

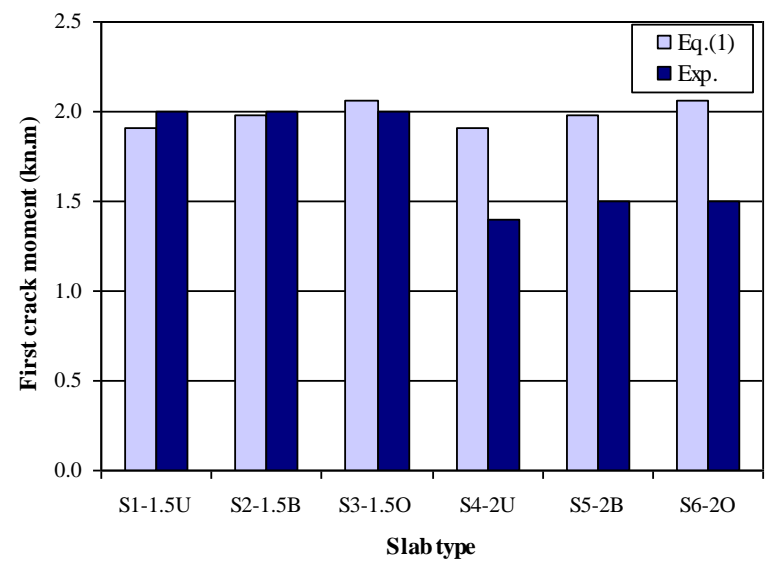

Fig. (8) Theoretical and Experimental first Crack moment for slabs (S4-S7)

Table (4) Theoretical $1{ }^{\text {st }}$ crack moment and crack width for GFRP reinforced slabs

\begin{tabular}{|c|c|c|}
\hline $\begin{array}{c}\text { Slab } \\
\text { Code }\end{array}$ & $\begin{array}{c}\text { Theoretical } 1^{\text {st }} \text { crack } \\
\text { Moment }(\mathrm{kN} . \mathrm{m})\end{array}$ & $\begin{array}{c}\text { Crack } \\
\text { width } \\
(\mathrm{mm})\end{array}$ \\
\hline S1-1.5U & 1.91 & 2.90 \\
\hline S2-1.5B & 1.98 & 2.19 \\
\hline S3-1.5O & 2.06 & 2.13 \\
\hline S4-2U & 1.91 & 2.90 \\
\hline S5-2B & 1.98 & 2.19 \\
\hline S6-2O & 2.06 & 2.13 \\
\hline
\end{tabular}

\subsection{Crack width}

Although the evaluation of crack width in steel reinforced concrete structures is attributed to the durability of structural element, it is significant in the design of GFRP reinforced concrete structure as a demand for structural integrity and serviceability requirements. As shown in Fig.(5), almost all first cracks were perpendicular to the direction of maximum stresses induced in the tension reinforcement at bending moment zone. As the increase of loads proceeds, a more cracks appears along the slabs and cracks continue growing in the pure bending zone. As a result of the shear stresses in shear spans, cracks appear inclined towards the central zone. The equation proposed by ACI 440.1R-06 for the calculation of crack width $\mathrm{w}$ is given by:

$$
w=2 \frac{\sigma_{f}}{E_{f}} \alpha \cdot k_{b} \sqrt{d_{c}^{2}+(s / 2)^{2}}
$$

Where: $\alpha$ is the ratio of the distance between the neutral axis and tension face to the distance between the neutral axis and the centroid of reinforcement, $k_{b}$ is a coefficient that takes into account the bond between the rebar and the concrete and can vary from 0.60 to $1.72, d_{c}$ is the thickness of cover from the tension face to the centre of the closest rebar, and $\mathrm{s}$ is the rebar spacing; Table (4) shows the theoretical values for first crack moment and the theoretical crack width for GFRP slabs. Fig.(9) shows the relation between loads and crack widths for slabs (S4, S5, and S6) for experimental results and ACI 440.1R-06 evolution. The results show a good agreement between experimental and theoretical predictions.
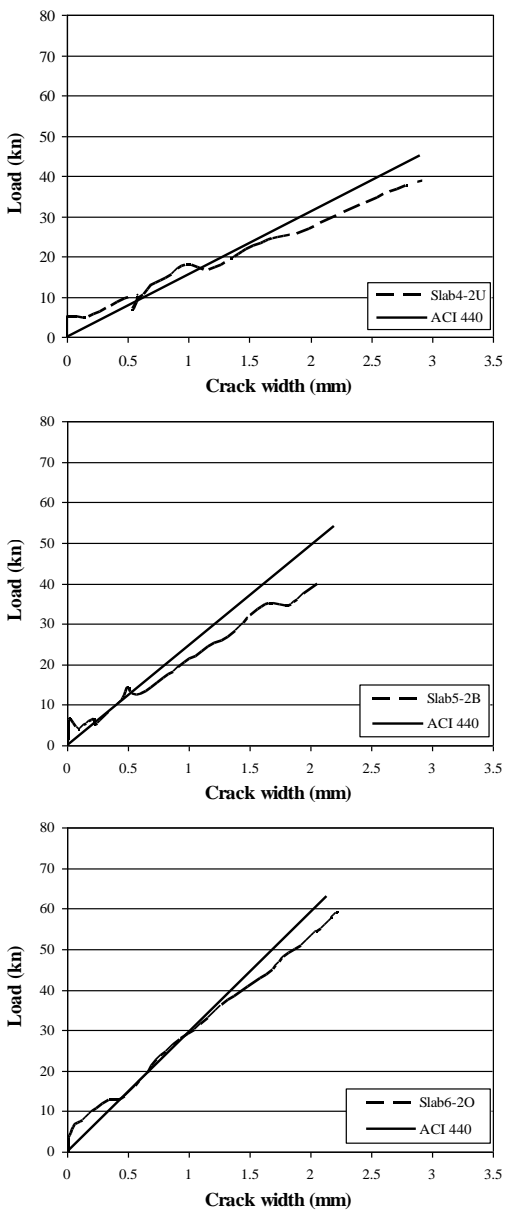

Fig. (9) Theoretical and Experimental crack width for slabs (S4, S5, and S6) 


\subsection{Load-deflection relations}

The load deflection curves for the tested slabs were recorded, and relations are shown in Fig. (10) Through Fig.(11). It is observed from both figures that a linear branch with a steep slope is detected in the uncracked condition of the slabs. A drop in the slope of the curves starts after the cracking stage up to the ultimate load capacity of slabs. In slabs (S4-S7), the curves stabilize after reaching ultimate loads until failure of slabs. It can be detected from the figures that reinforcement ratio, as well as $\mathrm{L}_{\text {sh }} / \mathrm{d}_{\text {eff }}$ ratio, affects the stiffness of slabs and hence affect the overall behavior of load-deflection curves. As expected, in all slabs, deformations decrease with the increase in reinforcement ratio. Also, for the same reinforcement ratio, higher $\mathrm{L}_{\mathrm{sh}} / \mathrm{d}_{\mathrm{eff}}$ leads to higher deformations in slabs.

In Fig. (10), Load deflection curves for specimens with $\mathrm{L}_{\mathrm{sh}} / \mathrm{d}_{\text {eff }}$ in the range of (5.4-5.6) are plotted. Slab 1; under reinforced slab (URFS); reached an ultimate load of $59.3 \mathrm{kN}$ and a corresponding vertical deflection of $33.3 \mathrm{~mm}$. Slab 2; balanced reinforced slab (BRFS); reached an ultimate load of $65.7 \mathrm{kN}$ and a corresponding vertical deflection of 29.1 $\mathrm{mm}$. Slab 3; over reinforced slab (ORFS); reached an ultimate load of $76.0 \mathrm{kN}$ and a corresponding vertical deflection of $16.4 \mathrm{~mm}$.

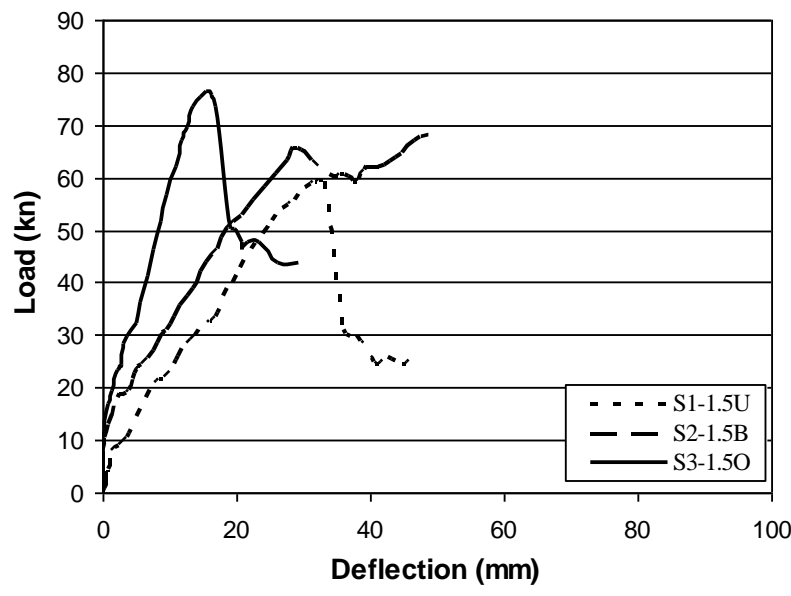

Fig. (10) Load-Deflection curves for slabs S1, S2, and S3

The load-deflection curves for slabs with $\mathrm{L}_{\text {sh }} / \mathrm{d}_{\text {eff }}$ in the range of (7.5-7.8) are shown in Fig. (11). Slab 4; URFS; reached an ultimate load of $38.7 \mathrm{kN}$ and a corresponding vertical deflection of $82.5 \mathrm{~mm}$. Slab 5; BRFS; reached an ultimate load of $39.9 \mathrm{kN}$ and a corresponding vertical deflection of $49.7 \mathrm{~mm}$. Slab 6; ORFS; reached an ultimate load of $59.0 \mathrm{kN}$ and a corresponding vertical deflection of $48.6 \mathrm{~mm}$. Slab 7; steel reinforced slab with under reinforced ratio; reached an ultimate load of $28.4 \mathrm{kN}$ and a corresponding vertical deflection of $29.1 \mathrm{~mm}$.

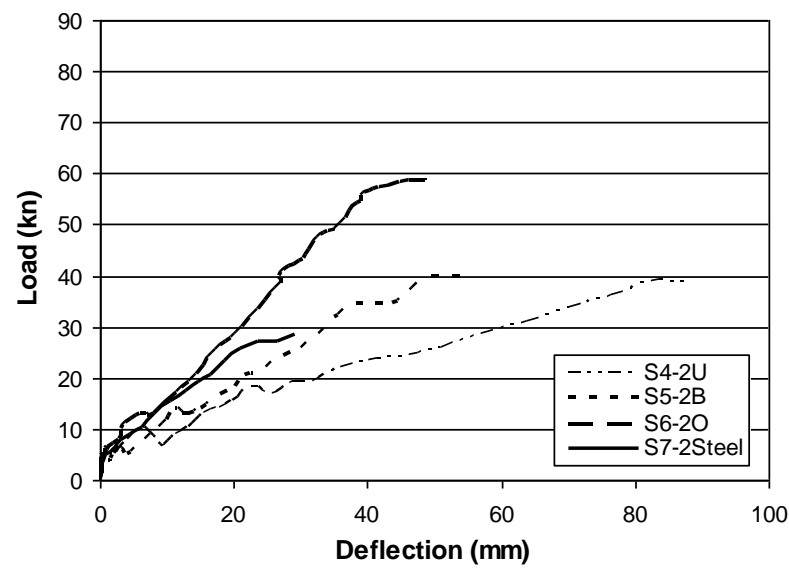

Fig. (11) Load-Deflection curves for slabs S4, S5, S6, and S7

As shown in Fig. (10) and Fig. (11), the increases in GFRP reinforcement ratio lead to an increase in the ultimate load capacity of the tested slabs and decrease in the deflection values. Considering slabs (1-3); $\mathrm{L}_{\mathrm{sh}} / \mathrm{d}_{\text {eff }}$ equal (5.4-5.6); the percentage increase in ultimate load capacities were $111 \%$, and $128 \%$ over the URFS (S1) for Balanced slab (S2) and ORFS (S3) respectively. The percentages of deflections at ultimate loads measured at mid span of beams compared to deflection of URFS (S1) were $87 \%$ and $49 \%$ for BRFS (S2) and ORFS (S3) respectively. Considering slabs (46); $\mathrm{L}_{\mathrm{sh}} / \mathrm{d}_{\text {eff }}$ equal (7.5-7.8); the percentage increase in ultimate load capacities were $103 \%$, and $152 \%$ over the URFS (S4) for BRFS (S5) and ORFS (S6) respectively. The percentages of deflections at ultimate loads compared to deflection of URFS (S4) were $60 \%$ and $59 \%$ for BRFS (S5) and ORFS (S6) respectively.

Similar to the effect of GFRP reinforcement ratio, the increase in the $\mathrm{L}_{\mathrm{sh}} / \mathrm{d}_{\text {eff }}$ for the same slab configuration leads to a decrease in ultimate load capacity and an increase in ductility of the slabs. The ultimate load capacity of slab (S4) is $65 \%$ of slab (S1) while its deflection is $248 \%$ of the same slab. The ultimate load capacity of slab (S5) is $61 \%$ of slab (S2) while its deflection is $171 \%$ of the same slab. The ultimate load capacity of slab (S6) is $78 \%$ of slab (S3) while its deflection is $296 \%$ of the same slab.

ACI 440.1R-06 for FRP reinforced concrete elements [21], provides a modified version of Branson's equation to evaluate theoretical prediction of 
deflection. Branson's equation represents an expression for the calculation of effective moment of inertia $\left(I_{e}\right)$.

The value of $I_{e}$ is in the boundary between the gross moment of inertia $\left(I_{g}\right)$ and the transformed cracked section $\left(I_{c r}\right)$.

$I_{e}=\left(\frac{M_{c r}}{M}\right)^{3} \beta_{d} I_{g}+\left[1-\left(\frac{M_{c r}}{M}\right)^{3}\right] I_{c r} \leq I_{g}$

Where $M_{c r}$ the cracking moment of the section is, $M$ is the moment in the member, $\beta_{d}$ is a reduction coefficient relatd to the reduced tension stiffening exhibited by FRP-reinforced members.

$\beta_{d}=\frac{1}{5}\left(\frac{\rho_{f}}{\rho_{f b}}\right) \leq 1.0$

Where $\rho_{f}$ is the FRP reinforcement ratio and $\rho_{f b}$ is the FRP reinforcement ratio produced balanced reinforcement ratio.

For the case of the tested beams in this research work, that is a simply supported beam of span $L$, with two point loads $P / 2$ applied at a distance $a$ from the supports, the maximum deflection is calculated from:

$\delta_{\max }=\frac{P a}{48 E_{c} I_{e}}\left(3 L^{2}-4 a^{2}\right)$

Where $E_{c}$ is the modulus of elasticity of concrete and $I_{g}$ is the effective moment of inertia of the crosssection, calculated by Eq. (4). Fig. (9) Shows load deflection curves for both experimental results and theoretical results using ACI 440.1R-6.

Toutanji and Saafi, [22, 23] modified the power factor of Branson's equation to account for the modulus of elasticity of the rebar and reinforcement ratio of their experimental results (they tested three sets of GRRP reinforced concrete beams with $I_{g} / I_{c r}$ ratios of 13 to 23 ):

$I_{e}=\left(\frac{M_{c r}}{M}\right)^{m} I_{g}+\left(1-\left(\frac{M_{c r}}{M_{a}}\right)^{m}\right) I_{c r} \leq I_{g}$ (7)

$$
\begin{aligned}
& m=6-\frac{10 E_{f}}{E_{s}} \rho_{f} \text { if } \frac{E_{f}}{E_{s}} \rho_{f}<0.3 \\
& m=3 \text { if } \frac{E_{f}}{E_{s}} \rho_{f} \geq 0.3
\end{aligned}
$$

Bischoff [24, 25] used the integration of curvature along the beam to propose an equation for $I_{e}$. The proposed equation took into account the tension-stiffening effect.

$$
I_{e}=\frac{I_{c r}}{1-\left(1-\frac{I_{c r}}{I_{g}}\right)\left(\frac{M_{c r}}{M}\right)^{2}}
$$

Fig. (12) Shows load deflection curves for both experimental results and theoretical results using Toutanji and Bischoff predictions.

Comparing the theoretical predictions with experimental data, it is obvious that they compare well up to service loads, which is taken as $35 \%$ of the ultimate loads. For higher loads, the theoretical approach deviates somewhat from the experimental relation as a result of the fundamental design concept of the theoretical approach which is serviceability conditions. This approach considers the linear stressstrain relationship for concrete and neglects other contributing effects on deflection rather than flexure itself.

\subsection{Strain profile along GFRP rebars}

Fig. (13) Shows the experimental profiles of strains along a central rebar located in each tested slab. The development of cracks leads to the increase in rebar strains, which is dominant at mid span of the slabs and nearby regions. From the figures, it is noted that strains in GFRP decrease as the reinforcement ratio increases. For slabs (S1-S3), where $\mathrm{L}_{\mathrm{sh}} / \mathrm{d}_{\mathrm{eff}}$ equal (5.45.6), the strains in GFRP rebars are less than strains in URFS (S1) by $43 \%$ and $59 \%$ for BRFS (S2) and ORFS (S3) respectively. Also, for slabs (S4-S6), where $\mathrm{L}_{\mathrm{sh}} / \mathrm{d}_{\mathrm{eff}}$ equal (7.5-7.8), the strains in GFRP rebars are less than strains in URFS (S4) by $33 \%$ and $60 \%$ for BRFS (S5) and ORFS (S6) respectively.

The increase in $\mathrm{L}_{\mathrm{sh}} / \mathrm{d}_{\mathrm{eff}}$ can effectively increase the ductility of slabs. When, $\mathrm{L}_{\mathrm{sh}} / \mathrm{d}_{\mathrm{eff}}$ increase from 5.5 

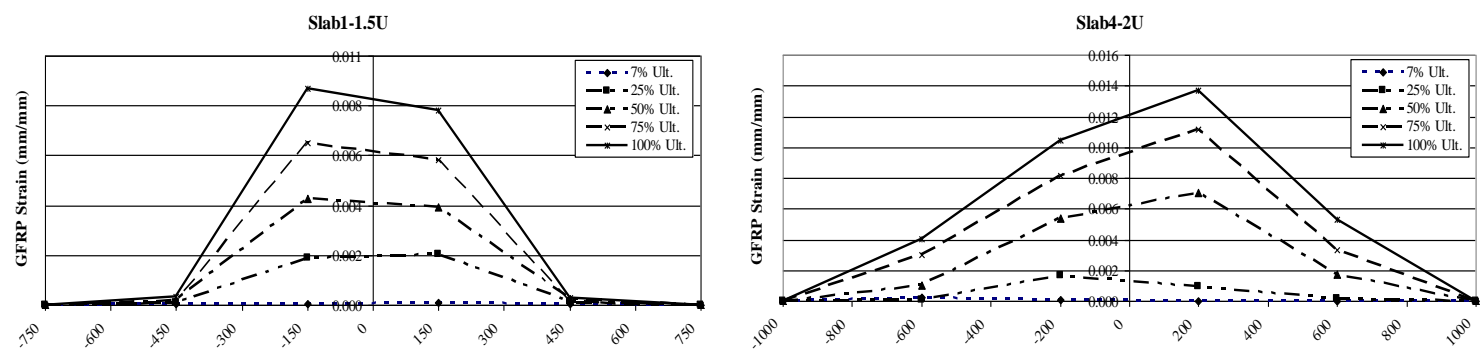

Distance from Center $(\mathrm{mm})$

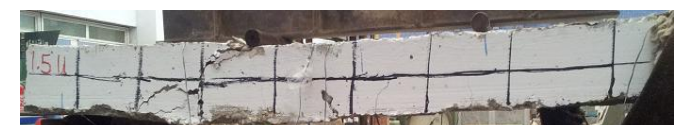

Distance from Center (mm)

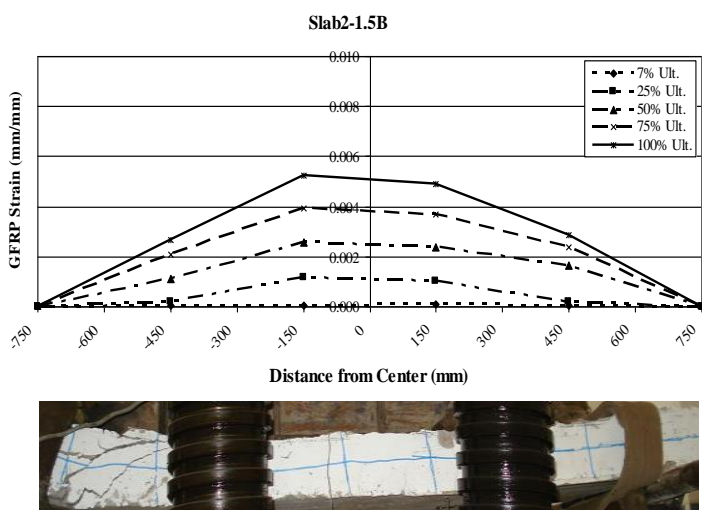

Slab3-1.50
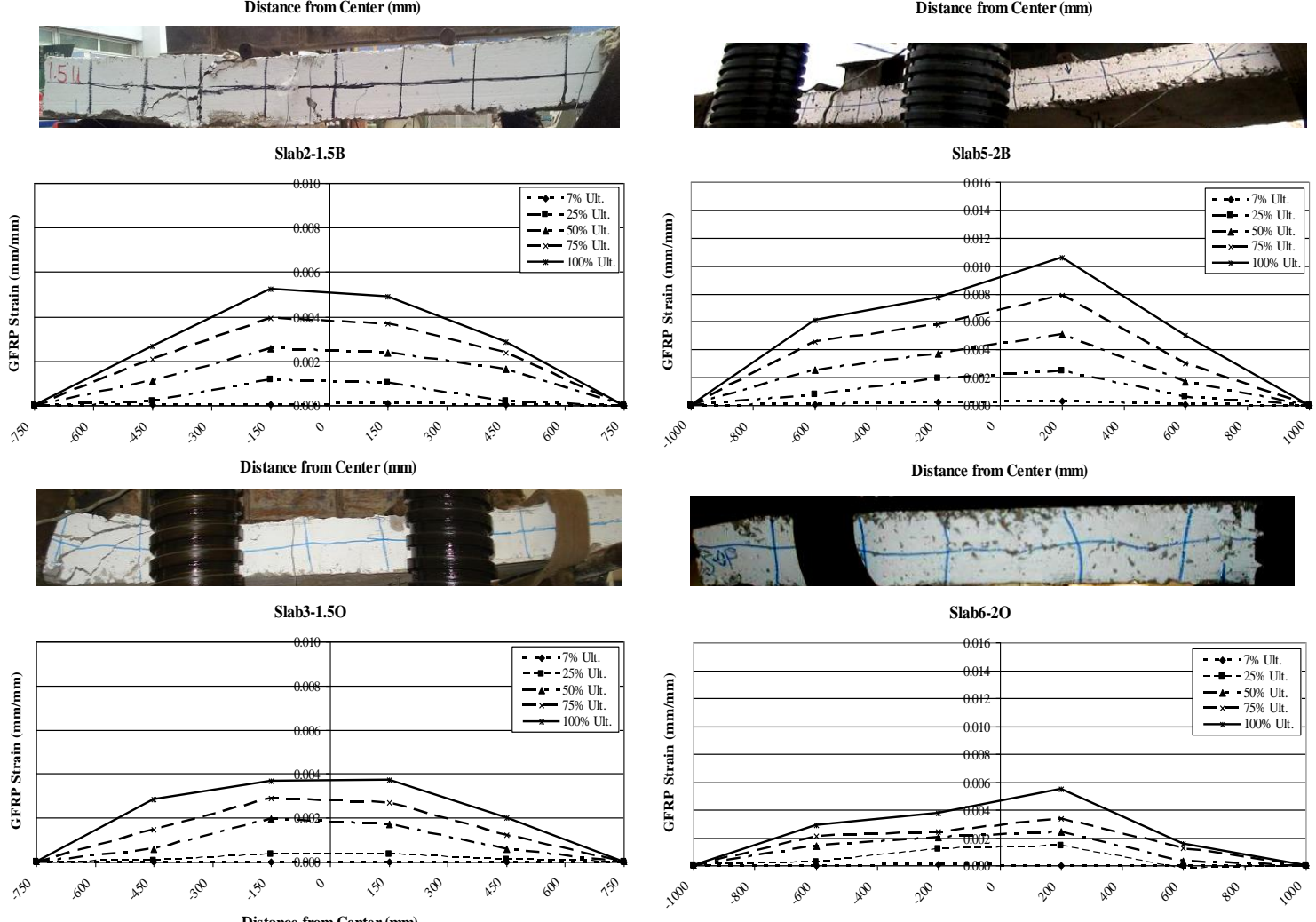

Slab6-20

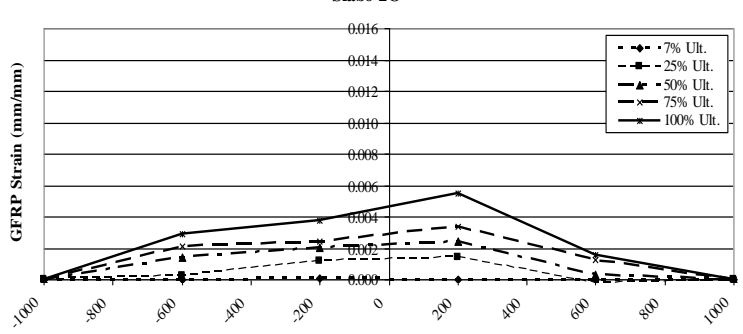

Distance from Center $(\mathrm{mm})$
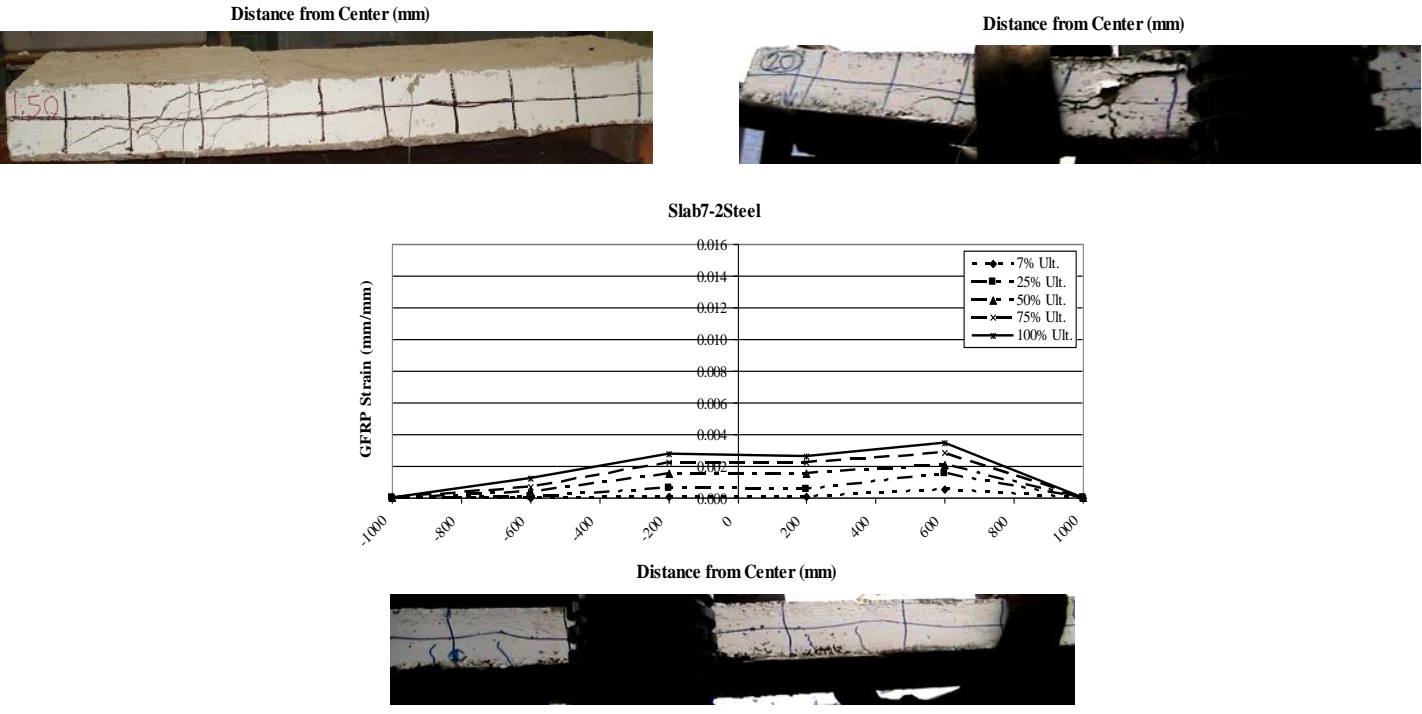

Fig. (13) Strain Profile along GFRP rebar for (S1-S7). 
to 7.7 , the gain in ductility is $50 \%, 102 \%$, and $47 \%$ for URFS, BRFS, and ORFS respectively.

\subsection{Ultimate load and moment capacity}

Theoretical ultimate loads for slabs were calculated according to ACI 440.1R-06 provision [21]. The approach of the code was based on the forces equilibrium, strain compatibility of sections and considers the equivalent stress block. The equations of moment capacity depend on whether the reinforcement ratio is lesser or higher than the balanced ratio:

$\rho_{f}=\frac{A_{f}}{b d}$

$\rho_{f b}=0.85 \beta_{1} \frac{f_{c}^{\prime}}{f_{f u}} \frac{E_{f} \varepsilon_{c u}}{E_{f} \varepsilon_{c u}+f_{f u}}$

When $\rho_{f}<\rho_{f b}$

$M_{n}=0.8 A_{f} f_{f u}\left(d-\frac{\beta_{1} c_{b}}{2}\right)$

$c_{b}=\left(\frac{\varepsilon_{c u}}{\varepsilon_{c u}+\varepsilon_{f u}}\right) d$

When $\rho_{f}>1.4 \rho_{f b}$

$f_{f}=\left(\sqrt{\frac{\left(E_{f} \varepsilon_{c u}\right)^{2}}{4}+\frac{0.85 \beta_{1} f_{c}^{\prime}}{\rho_{f}} E_{f} \varepsilon_{c u}}-0.5 E_{f} \varepsilon_{c u}\right) \leq f_{f u}$

$M_{n}=A_{f} f_{f}\left(d-\frac{a}{2}\right)$

$a=\frac{A_{f} f_{f}}{0.85 f_{c}^{\prime} b}$

Also, $M_{n}$ can be calculated from

$M_{n}=\rho_{f} f_{f}\left(1-0.59 \frac{\rho_{f} f_{f}}{f_{c}^{\prime}}\right) b d^{2}$

Theoretical and experimental ultimate loads are compared in Table5.

\subsection{Ductility and deformability factor}

Contrary to the traditional steel reinforced concrete slabs, where ductility can be measured as the total deformation divided by deformation at failure stage divided by deformation at yielding stage, the
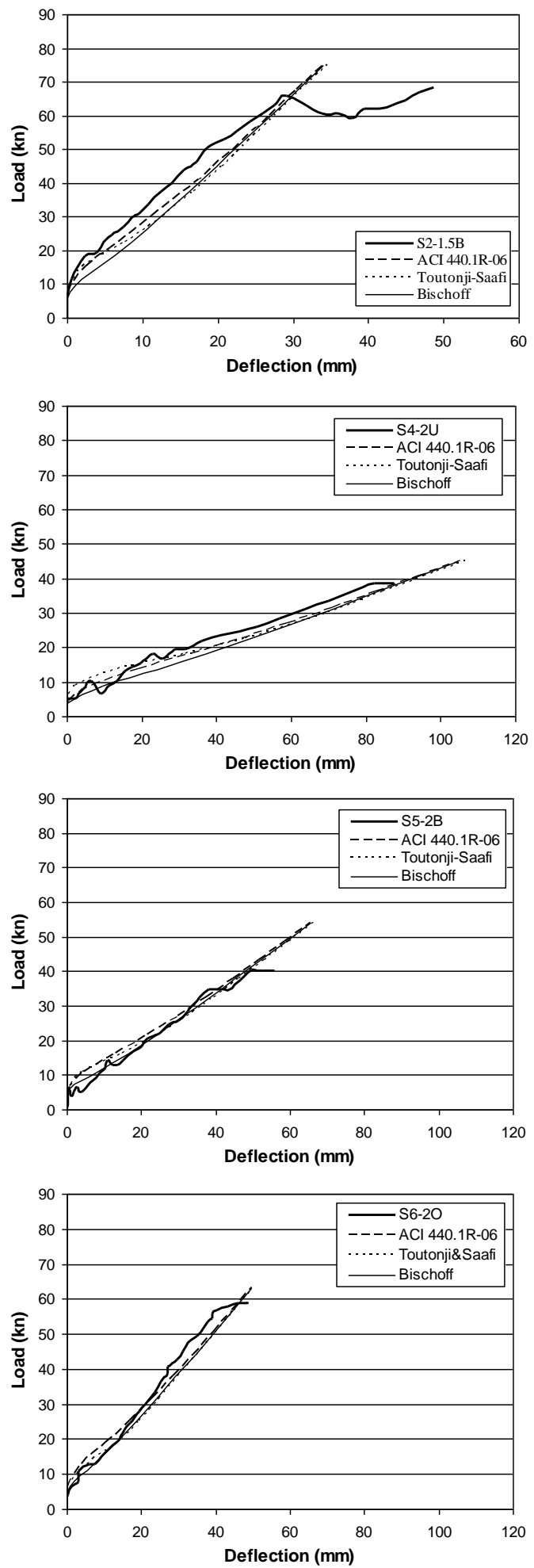

Fig. (12) Experimental Load-Deflection curves vs. theoretical load-deflection curves for GFRP reinforced slabs 
GFRP reinforced slabs behave more linearly until failure and such a traditional method can not be applied to estimate ductility. The ISIS [8] proposal takes into account the moment and curvature of flexure elements at both surface and ultimate stages. This method is considered as an accurate method for the calculation of the so-named deformability, and it is recommended that this factor is not less than 4. The deformability factor by ISIS can be represented in the following:

Table 5. Ultimate theoretical and experimental loads

\begin{tabular}{|c|c|c|c|}
\hline $\begin{array}{c}\text { Slab } \\
\text { Code }\end{array}$ & $\begin{array}{c}\text { Pu ACI } \\
440(\mathrm{kN})\end{array}$ & $\begin{array}{c}\text { Pu exp. } \\
(\mathrm{kN})\end{array}$ & $\begin{array}{c}\text { Pu exp. } \\
\text { Pu ACI } \\
440\end{array}$ \\
\hline S1-1.5U & 42.00 & 59.30 & 1.41 \\
\hline S2-1.5B & 50.00 & 65.70 & 1.31 \\
\hline S3-1.5O & 59.00 & 76.00 & 1.29 \\
\hline S4-2U & 30.00 & 38.70 & 1.29 \\
\hline S5-2B & 36.00 & 39.90 & 1.11 \\
\hline S6-2O & 42.00 & 59.00 & 1.40 \\
\hline
\end{tabular}

Deformability Factor $=\frac{(\text { Moment } \times \text { Curvature })_{\text {Ultimate State }}}{(\text { Moment } \times \text { Curvature })_{\text {Service State }}}$

The curvature was calculated using the maximum actual experimental concrete strain, rather that the theoretical value. Also, the ultimate moment is given as the maximum one recorded during testing. Table (6) shows the results of deformability factor for all GFRP reinforced beams.

As can be deduced from table (6), the deformability factor depends on the reinforcement ratio of slabs, and it is obvious that all values are more that the recommended one which is 4 . As expected, the deformability, hence ductility decreases with an increase in reinforcement ratios.

Table 6. Deformability factor for GFRP reinforced slabs

\begin{tabular}{|c|c|c|c|c|c|}
\hline \multirow{2}{*}{$\begin{array}{l}\text { Slab } \\
\text { Code }\end{array}$} & \multicolumn{2}{|c|}{ Ultimate Load } & \multicolumn{2}{|c|}{ Service Load } & \multirow{2}{*}{$\begin{array}{l}\text { Deformability } \\
\text { Factor (Eq. 19) }\end{array}$} \\
\hline & $\begin{array}{c}\text { Moment } \\
(\mathrm{kN} \cdot \mathrm{m})\end{array}$ & Curvature $\left(\times \mathrm{m}^{-1}\right)$ & $\begin{array}{l}\text { Moment } \\
(\mathrm{kN} . \mathrm{m})\end{array}$ & Curvature $\left(\times \mathrm{m}^{-1}\right)$ & \\
\hline S1-1.5U & 12.80 & 0.244 & 5.10 & 0.030 & 20.4 \\
\hline S2-1.5B & 14.10 & 0.114 & 5.60 & 0.021 & 13.8 \\
\hline S3-1.50 & 16.30 & 0.064 & 6.50 & 0.014 & 11.5 \\
\hline S4-2U & 11.60 & 0.245 & 4.60 & 0.035 & 17.7 \\
\hline S5-2B & 12.00 & 0.113 & 4.80 & 0.018 & 15.7 \\
\hline $\mathrm{S} 6-2 \mathrm{O}$ & 18.00 & 0.064 & 7.20 & 0.014 & 11.9 \\
\hline
\end{tabular}

\section{Conclusions}

In this research work, 6 slabs reinforced with GFRP rebars and 1 steel reinforced slab was tested in 2 point bending considering reinforcement ratio and shear span to effective depth ratio as the main parameters. The data recorded during tests were analyzed, and prediction models were applied. From the analysis of both experimental and analytical work, the following conclusions can be drawn:

- GFRP reinforced slabs showed a bilinear elastic behavior up to failure and the increase in reinforcement ratio lead to a less deflection in all tested slabs.

- As concluded from analysis of slabs at serviceability level, the flexural deflection predictions provided by ACI 440.1R-6, Toutanji and Saafi, and Bischoff are close to the experimental data for all tested slabs. For higher loads, slabs with $\mathrm{L}_{\mathrm{sh}} / \mathrm{d}_{\mathrm{eff}}$ ratio equal (7.5-7.8) showed a close agreement with experimental work than slabs with $\mathrm{L}_{\mathrm{sh}} / \mathrm{d}_{\mathrm{eff}}$ equal (5.4-5.6).

- The parameters chosen in the experimental work (Reinforcement ratio and shear span to effective depth ration) influence the effective stiffness of slabs and, therefore, affect its load deflection curves. The analytical methods used were able to simulate the behavior of slabs from serviceability point of view.

- Crack width using the minimum $k_{b}$ value in ACI 440.1R-06 equations gave a good agreement with experimental results especially for slabs having a higher shear span to effective depth ratio.

- The experimental ultimate loads of slabs are higher than that derived from ACI 440.1R-06 with an average value of $30 \%$. This implies that strains in the compression zone of slabs are dominant in order to get accurate analytical values.

- A high degree of ductility, represented by deformability factors in GFRP reinforced slabs, was attained in the tested slabs and all values were more than 4 .

\section{Acknowledgments}

The author would like to express his gratitude and appreciation to the students of HTI and National Center for Research in Construction and Housing, Egypt, of great help in the experimental program. 


\section{References}

[1] Murphy J. In: Reinforced plastics handbook. Amsterdam: Elsevier; 1998.

[2] White T.D., editor, Composite materials and structural plastics in civil engineering construction, Proceedings of the Materials Engineering Congress, New York: American Society of Civil Engineers; 1992. pp. 532-718.

[3] Non-metallic reinforcement for concrete structures-FRPRCS-5. In: Burgoyne C, editor. Proceedings of International Conference, Cambridge,UK.

[4] Makhtouf, H. M., Ahmadi, B.H., and Al-Jabal, J., "Preventing Reinforced Concrete Deterioration in the Arabian Gulf', Concrete International, V.13, No. 5, May 1991, pp. 65-67.

[5] Federation International du Beton, FIB, Task Group 9.3, FRP reinforcement in RC structures, Lausanne, Switzerland; 2007.

[6] Barris C., Torres Ll., Turon A., Baena M., Catalan A.,"An experimental study of the flexural behaviour of GFRP RC beams and comparison with prediction models", J. Composite Structures, 91, 2009, pp. 286-295.

[7] Pilakoutas K., Neocleous K., Guadagnini M., "Design philosophy issues of fiber reinforced polymer reinforced concrete structures", J. Compos. Constr., 2002;6(3), p.p.154-61.

[8] ISIS Canada., "Reinforcing concrete structures with fiber-reinforced polymers - design manual no. 3", Manitoba, Canada: ISIS Canada Corporation, 2001.

[9] ACI Committee 318, "Building code requirements for structural concrete (ACI 318-08) and commentary (ACI 318R-08)", Farmington Hills (Mich, USA), American concrete institute, 2008.

[10] CEB, "CEB-FIP Model Code 1990", Comite EuroInternational du Beton, Thomas Telford Ltd, 1993.

[11] CEN, "Eurocode 2: Design of concrete structures Part 1-1: General rules and rules for buildings (EN 1992-1-1:2004)", European committee for standardization, 2004.

[12] fib Bulletin No. 40, "FRP reinforcement in RC structures", International federation for structural concrete, Lausanne, Switzerland, 2007.

[13] Al-Sunna R., Pilakoutas K., Hajirasouliha I., Guadagnini M., "Deflection behaviour of FRP reinforced concrete beams and slabs: An experimental investigation", Composites Part B: Engineering, 2012, Volume 43, Issue 5, pp. 21252134.

[14] Thériault M., Benmokrane B., "Effects of FRP reinforcement ratio and concrete strength on flexural behaviour of concrete beams", ASCE J Compos Constr., 1998; 2(1), pp.7-16.

[15] Masmoudi R., Thériault M., Benmokrane B., "Flexural behavior of concrete beams reinforced with deformed fiber reinforced plastic reinforcing rods", ACI Struct J., 1998;95(6), pp.665-76.

[16] Rafi M.M., Nadjai A., Ali F., Talamona D., "Aspects of behaviour of CFRP reinforced concrete beams in bending". Constr Build Mater., 2008;22, pp.277-85.

[17] ASTM C496-96, "Standard test method for splitting tensile strength of cylindrical concrete specimens", ASTM Committee (Philadelphia), 1996.

[18] ASTM C469-94, "Standard test method for static modulus of elasticity and poisson's ratio of concrete in compression", ASTM Committee (Philadelphia), 1994.

[19] Alsayed SH, Al-Salloum YA, Almusallam TH. "Performance of glass fiber reinforced bars as reinforcing material for concrete structures", Composites: Part B, 2000;31, pp.555-67.

[20] ACI 435R-95, "Control of deflection in concrete structures", American concrete institute, 1995.

[21]ACI Committee 440, "Guide for the design and construction of concrete reinforced with FRP Bars", (ACI 440.1R-06), Farmington Hills, Michigan (USA): American Concrete Institute; 2006.

[22] Toutanji, H. A., and Saafi, M., "Flexural behavior of concrete beams reinforced with glass fiberreinforced polymer (GFRP) bars", ACI Structural Journal, 2000,97(5),pp.712-719.

[23] Toutanji, H., and Deng, Y., "Deflection and crackwidth prediction of concrete beams reinforced with glass FRP rods", Construction and Building Materials, 2003,17(1), pp.69-74.

[24] Bischoff, P. H. "Reevaluation of deflection prediction for concrete beams reinforced with steel and fiber reinforced polymer bars." Journal of Structural Engineering, 2005,131(5), pp.752-762.

[25] Bischoff, P. H., "Deflection calculation of FRP reinforced concrete beams based on modifications to the existing branson equation", Journal of Compsites for Construction, 2007, 11(1), pp.4-14. 